\title{
Biosynthesis of Iron Oxide Nanoparticles using Aqueous Extract of Convolvulus Pluricaulis Plant, its Characterization and Acute Oral Toxicity Studies
}

\author{
Lakshmi Pravallika Poka*1, Krishna Mohan $\mathrm{G}^{1}$, Venkateswara Rao $\mathrm{K}^{2}$, \\ Shanker $\mathrm{K}^{1}$ \\ ${ }^{1}$ Centre for Pharmaceutical Sciences, IST, JNTUH, Hyderabad, Telangana-500085, India \\ ${ }^{2}$ Centre for Nano Science and Technology, IST, JNTUH, Hyderabad, Telangana-500085, India
}

\begin{abstract}
The synthesis of nanoparticles by green approach has been of great interest because of its ecofriendly and non-toxic potential in biomedical applications. The present study was aimed to synthesize Convolvulus pluricaulis iron oxide nanoparticles (CPIO) using its aqueous extract. The phytochemicals available in the aqueous extract acted as effective reducing agent and capping agent. The CPIO nanoparticles synthesized were characterized by PSA, XRD, FTIR, SEM and TEM. FTIR measurements showed the CPIO nanoparticles having a coating of phytochemical compounds indicating a possible role of biomolecules from Convolvulus pluricaulis for capping and efficient stabilization of the CPIO nanoparticles. The XRD spectrum confirmed the crystalline structure of CPIO nanoparticles with an average particle size of $32.8 \mathrm{~nm}$.The synthesized CPIO nanoparticles are found to be agglomerated porous nanoparticles from the SEM and TEM images. Acute oral toxicity studies were carried out for a period of 14 days and no mortality was observed during this treatment period. As no synthetic reagents were used in this method, the synthesized CPIO nanoparticles are non-toxic, biocompatible so have potential biomedical applications.
\end{abstract}

Keywords: Green synthesis, Convolvulus pluricaulis, Characterization techniques, Acute oral toxicity studies, Biomedical applications.

\section{Introduction}

Nanotechnology is evolving as a rapidly growing field with its application in science and technology for the purpose of synthesizing new materials at the nanoscale level ${ }^{1}$. The synthesis of iron oxide nanoparticles has been extensively developed in the past decade with numerous applications such as, bio sensing applications ${ }^{2}$, catalysis ${ }^{3,4}$, magnetic storage media ${ }^{5}$, targeted drug delivery ${ }^{6-9}$, and contrast agents in Magnetic Resonance Imaging ${ }^{10-12}$. Currently, a large number of physical, chemical, biological, and hybrid methods are available to synthesize different types of nanoparticles that show specific properties ${ }^{13}$. These physical, chemical methods need hazardous chemicals and high energy requirements for synthesis of nanoparticles. It is very widely known that nanoparticles synthesized with plant extracts already have a functionalized surface that contains the biological components of plant like proteins, polysaccharides, organic ligands, and polyatomic alcohols which are absent in nanoparticles synthesized by physical and chemical methods ${ }^{14,15}$.

The presence of these biological components improves the stability of the nanoparticles synthesized and if required, may also facilitate the subsequent attachment of functional molecules, such as drugs, antibodies or $\mathrm{DNA}^{16}$. So comparing the above-cited methods, synthesizing nanoparticles via plants is a relatively economical and eco-friendly approach.

Convolvulus pluricaulis is a perennial herb belongs to the family "Convolvulaceae", commonly known as "Shankhapushpi" and seems to be like morning glory ${ }^{17}$. The plant contains several active constituents such as alkaloid (Shankhapushpine), triterpenoids, flavonoids, glycosides, anthocyanins, phenolics and steroids ${ }^{18,19}$.

Convolvulus pluricaulis has been proved for its potential for centuries in Ayurvedic medicine to treat central nervous system depression, anxiolytic ${ }^{20}$, tranquilizing, anti-depressant ${ }^{21}$, neurodegenerative, anti-stress, anti-amnesic ${ }^{22}$, anti-fungal, anti-bacterial, antioxidant ${ }^{23}$, anticonvulsant ${ }^{24}$, immunomodulatory, analgesic, hypolipidemic, anti-ulcer and cardiovascular activity ${ }^{25,26}$.

There are also reports on the synthesis of silver nanoparticles using various extracts of Convolvulus pluricaulis ${ }^{27}$. The IONPs has unique properties, such as being superparamagnetic, biocompatible, biodegradable, and non-toxic to humans which make them to have a potential in biomedical applications $\mathrm{s}^{28-30}$.

Based on the literature review, there are still no specific researches done on aqueous extract of whole plant of Convolvulus pluricaulis for the iron oxide nanoparticle synthesis, and this inspires and motivates us to work on this. Hence, in this work, a novel green method of synthesizing CPIO nanoparticles using Convolvulus pluricaulis aqueous extract, characterizing them and evaluating their acute oral toxicity is proposed. 


\section{Materials and Methods}

Convolvulus pluricaulis plant was purchased from authorized medicinal plant dealer in Hyderabad, Telangana. In synthesis process, the chemicals used like Ferric chloride hexa-hydrate $\left(\mathrm{FeCl}_{3} \cdot 6 \mathrm{H}_{2} \mathrm{O}\right)$, ferrous chloride tetra-hydrate $\left(\mathrm{FeCl}_{2} \cdot 4 \mathrm{H}_{2} \mathrm{O}\right)$ were purchased from Sigma-Aldrich, USA and all other chemicals used in synthesis and acute oral toxicity studies were of analytical grade.

\section{Preparation of aqueous extract of Convolvulus pluricaulis whole plant}

The whole plant of Convolvulus pluricaulis was initially rinsed thrice in distilled water and allowed to dry completely at room temperature. The whole plant was made into coarse powder using maple mixer. The extraction was carried out by packing $250 \mathrm{~g}$ of plant powder in the soxhlet apparatus using distilled water as solvent for 18 hours. The aqueous extract was concentrated using rotary evaporator (Heidolph, USA) and crude extract was stored at $4^{\circ} \mathrm{C}$ until further use.

\section{Synthesis of iron oxide nanoparticles using aqueous extract of Convolvulus pluricaulis}

CPIO nanoparticles were synthesized by dissolving $\mathrm{FeCl}_{3} \cdot 6 \mathrm{H}_{2} \mathrm{O}$ and $\mathrm{FeCl}_{2} \cdot 4 \mathrm{H}_{2} \mathrm{O}$ in $2: 1$ Molar ratio in $100 \mathrm{~mL}$ of sterile distilled water and heated to $80^{\circ} \mathrm{C}$ with mild stirring at $500 \mathrm{rpm}$ using magnetic stirrer results in formation of yellow colored solution. After 10 minutes of stirring, $5 \mathrm{~mL}$ of the Convolvulus pluricaulis aqueous extract was added to the mixture, immediately the yellowish colour of the mixture changed to reddish brown colour. After 5 minutes, $1 \mathrm{M}$ sodium hydroxide was added to the mixture dropwise at the rate of $3 \mathrm{ml} / \mathrm{min}$ to allow the precipitation of iron oxide uniformly and reddish brown mixture changed to black suspended particles confirming the green synthesis of iron oxide nanoparticles shown in Figure 1. The mixture was allowed to cool down to room temperature. The synthesized CPIO nanoparticles were purified by dispersing in distilled water and dried overnight in hot air oven at $80^{\circ} \mathrm{C}$. CPIO nanoparticles were stored at room temperature until further use ${ }^{31}$.

\section{Characterization of synthesized CPIO nanoparticles}

The crystalline structure and phase purity of the synthesized CPIO nanoparticles were examined by Xray diffraction measurement over the $2 \theta$ range of $20-70^{\circ}$ (Bruker D8 X-ray Diffractometer). To determine particle size distribution of synthesized CPIO nanoparticles, Particle size analyzer (HORIBA Scientific SZ-100) was used. For this, CPIO nanoparticles were resuspended in ethanol. Fourier transform infrared (FTIR) spectroscopy (Bruker) was used to report the presence of biomolecules responsible for the synthesis of CPIO nanoparticles. Dried CPIO nanoparticles were grinded with potassium bromide to produce pellet, which was examined in a wavelength range of $400-4000 \mathrm{~cm}^{-1}$. The morphology, particle size and shape of CPIO nanoparticles were evaluated using scanning electron microscopy (SEM), transmission electron microscope (TEM).The elemental composition of the CPIO nanoparticles was determined using energy dispersive X-ray (EDX).

\section{Acute oral toxicity studies}

The experiments were carried out according to the guidelines of the Committee for the Purpose of Control and Supervision of Experiments on Animals (CPCSEA), New Delhi, India on either sex of Swiss albino mice weighing 20-25g. The study was conducted after getting approval from the Institutional animal ethical committee of CMR College of pharmacy, Hyderabad (approval no: IAEC/1657/CMRCP/T2/PhD-16/47). Animals were acclimatized for a week before the commencement of acute oral toxicity studies under standard laboratory conditions (12L:12D cycle, air conditioned room at $25^{\circ} \mathrm{C} \pm 2^{\circ} \mathrm{C}$ temperature). The animals had free access to pellet diet procured from Vyas Labs, Hyderabad and water ad libitum.

The selected Swiss albino mice were divided into 2 groups of 3 animals in each. Test mice were fasted for $4 \mathrm{~h}$ before dosing with free access to water only. The control group received distilled water $(10 \mathrm{ml} / \mathrm{kg})$ and the test group received $2000 \mathrm{mg} / \mathrm{kg}$ b.w of CPIO nanoparticles.

Immediately after administration of dose, the mice were observed for the first $4 \mathrm{~h}$ for skin and fur changes, eye secretion, respiration, behavioral changes and death, if any, intermittently for the next $6 \mathrm{~h}$, then again at $24 \mathrm{~h}$ after dosing. Special attention was paid on the clinical signs of toxicity including convulsions, tremors, salivation, nausea, vomiting, diarrhea, lethargy, coma, etc. They were then kept under observation up to 14 days after drug administration to identify mortality, if any. The observations were made daily. In addition, the histopathological changes have been examined as well ${ }^{32}$.

\section{Histopathology studies}

After 2 weeks, mice were sacrificed by cervical dislocation, and tissues were collected. Brain, heart and liver were fixed in Bouin's fluid for $24 \mathrm{~h}$ and then into $70 \%$ ethanol, which was changed 3-4 times every day until the yellow color of Bouin's fluid completely disappeared. Tissues were hydrated serially in 80,90 , and 
$100 \%$ ethanol and stored in isopropanol overnight at $60^{\circ} \mathrm{C}$ before embedding in paraffin. Five micron sections were made for further analysis. Sections were deparaffinized by xylene and were re-hydrated serially in 100, 90, 80, 70, and 50\% ethanol, and then rinsed briefly in distilled water. Slides were immersed into Harris hematoxylin solution for $10 \mathrm{~min}$, subsequently washed in distilled water for a while and differentiated in $1 \%$ hydrochloric acid for $30 \mathrm{~s}$ and then immersed in $0.2 \%$ ammonia water for $30 \mathrm{~s}$ to $1 \mathrm{~min}$. After washing in running tap water for $10 \mathrm{~min}$, sections were counterstained with $0.2 \%$ eosin Y solution for $1 \mathrm{~min}$. Sections were washed in distilled water and followed by serial dehydration using 50, 70, 80, 90, and 100\% alcohol. Slides were cleaned with three changes of xylene and then mounted with mounting medium ${ }^{33}$.

IV. Synthesis of CPIO nanoparticles

\section{Results and Discussion}
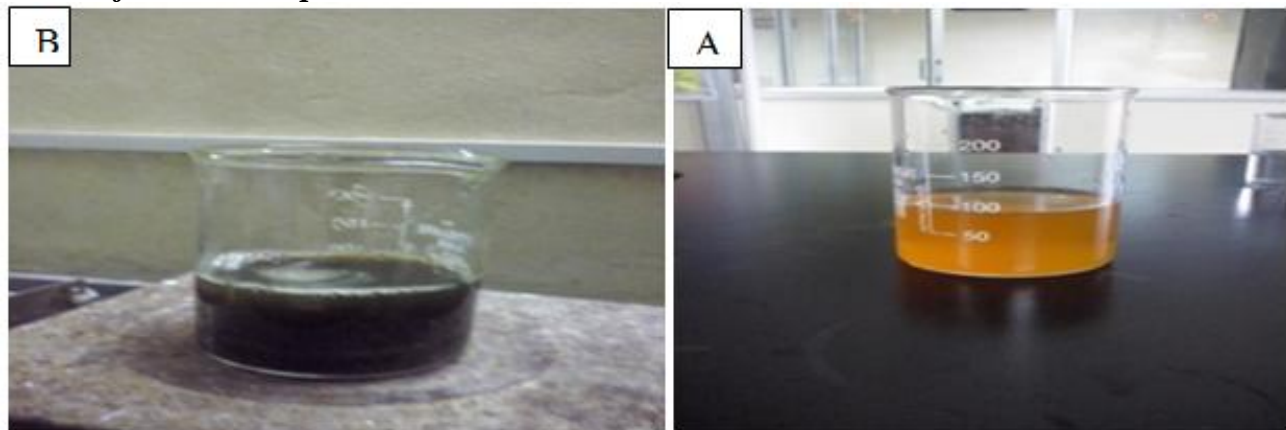

Figure 1. Iron chlorides solution color changed after addition of aqueous extract of Convolvulus pluricaulis from yellow (A) to dark reddish brown (B).

\section{XRD and PSA Analysis}

It is found that the presence of peaks at $2 \theta$ values $31.1^{\circ}, 34.1^{\circ}, 44.8^{\circ}, 57.4^{\circ}, 62.9^{\circ}, 68.3^{\circ}$ corresponds to (222), (311), (411), (428), (440), (603) planes of iron oxide nanoparticles (Figure 2-JCPDS NO: 89-5894) respectively. Thus, the XRD spectrum confirmed the crystalline structure of CPIO nanoparticles and found to be $\gamma-\mathrm{Fe}_{2} \mathrm{O}_{3}$. No peaks of other impurity crystalline phases have been detected. The average crystalline size of CPIO nanoparticles was estimated using the Debye-Scherrer equation and found to be around $32.8 \mathrm{~nm}$.

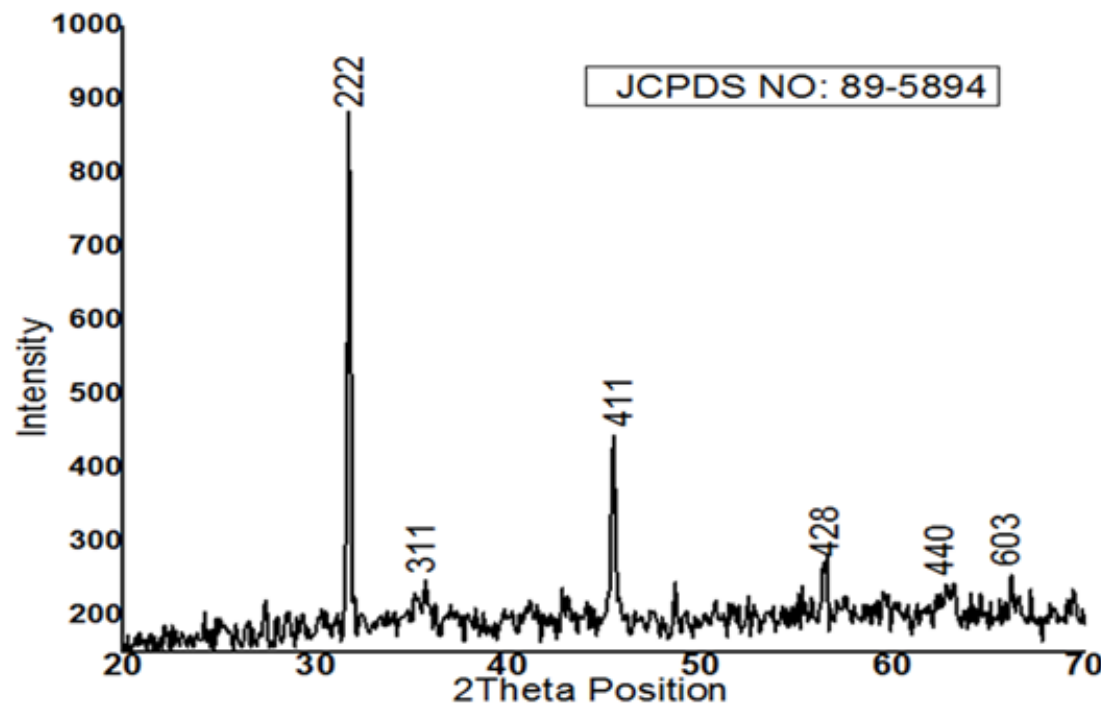

Figure 2. XRD pattern of synthesized CPIO nanoparticles

The particle size was analyzed using particle size analyzer. A small drop of the sample was dispersed in water and analyzed under laser light beams in a disposable sizing cuvette. The particle size was analyzed under the intensity of laser light on the sample particle. The average particle size distribution was found between 7-60 $\mathrm{nm}$. The mean particle size of CPIO nanoparticles synthesized was found to be $18 \mathrm{~nm}$ (Figure 3 ). 


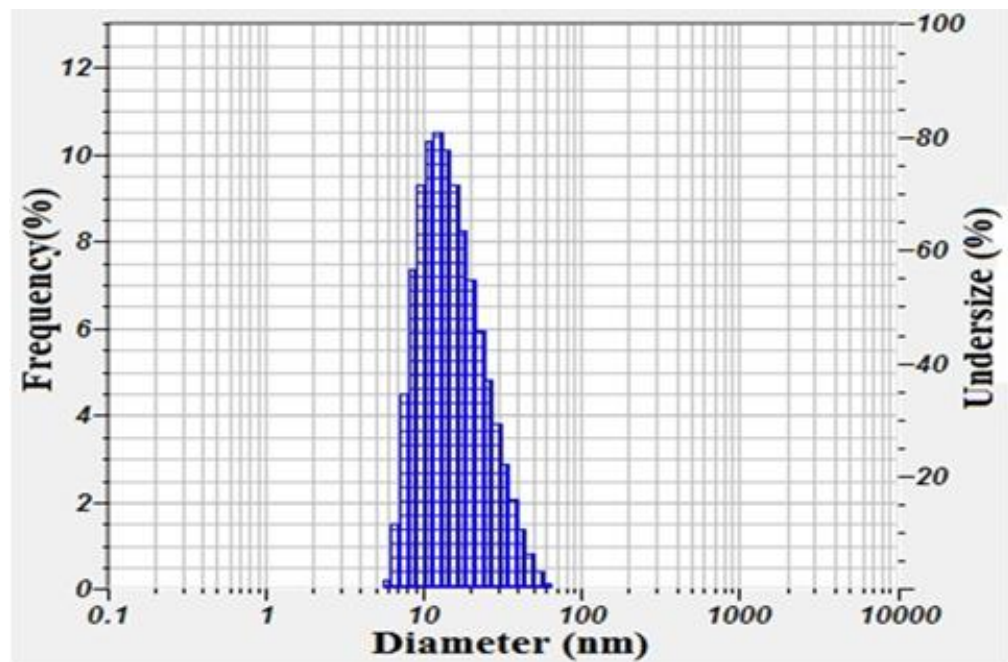

Figure 3. Particle size distribution of synthesized CPIO nanoparticles

\section{SEM and EDX Analysis}

The SEM image and EDX spectra for the CPIO nanoparticles are shown in Figure 4. SEM confirms that the CPIO nanoparticles are agglomerated particles because of the plant material coated over the iron oxide nanoparticles (Figure 4A). The Energy dispersive X-ray spectra was carried out to report the elemental composition of nanoparticle samples like iron $(\mathrm{Fe})$ and oxygen $(\mathrm{O})$, the peaks around $0.8,6.3$, and $7.1 \mathrm{keV}$ are related to the binding energies of Fe. Therefore, the EDX spectra confirmed the presence of iron oxide nanoparticles in the aqueous extract of Convolvulus pluricaulis without any impurity peaks (Figure 4B).
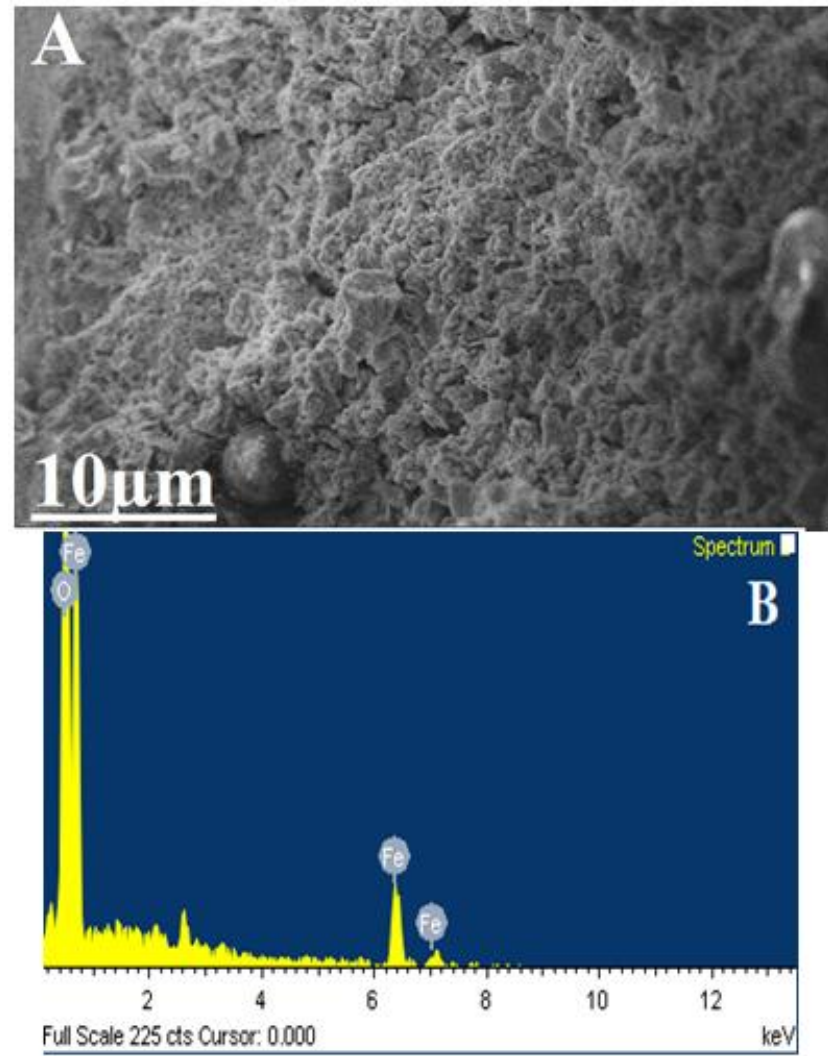

Figure 4. SEM image (A) and EDX spectra of synthesized CPIO nanoparticles (B).

TEM Study

The size and morphology of the synthesized CPIO nanoparticles were reported by using TEM. The TEM image of synthesized CPIO nanoparticles (Figure 5) showed that majority of the nanoparticles were porous in nature with nearly spherical shape. The image revealed that most of the particles were agglomerated, 
which might be due to the presence of plant material as a capping agent. Besides, the tendency of agglomeration is not surprising as the synthesized CPIO nanoparticles are small in size and possess magnetic characteristics. Porous spherical shaped iron oxide nanoparticles capped with plant material were more dominant at a scale range of $50 \mathrm{~nm}$.

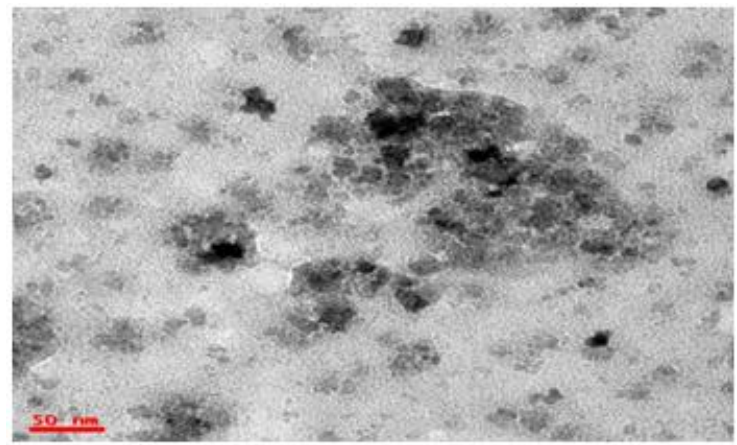

Figure 5. TEM image of synthesized CPIO nanoparticles

\section{FTIR Analysis}

FTIR measurement was carried out to identify the biomolecules responsible for capping and stabilization of the metal nanoparticles synthesized by Convolvulus pluricaulis was shown in Figure 6. FTIR analysis showed that the biosynthesized iron oxide nanoparticles were capped with bimolecular compounds which were responsible for reduction of iron oxide. The Spectra showed strong absorption bands at 3460.8, 2923.9, 2854.5, 1741.4, 1569.5, 1462.3, 1383.4, 1069.8, 1020.7, 849.5, 651.4, $605.8 \mathrm{~cm}^{-}{ }^{1}$. The absorption peak at $3460.8 \mathrm{~cm}^{-}{ }^{1}$ indicates $-\mathrm{OH}$ stretching, $2923.9 \mathrm{~cm}^{-}{ }^{1}$ indicates $\mathrm{C}-\mathrm{H}$ stretching vibration, 2854.5, 1741.4, $1569.5,1462.3,1383.4,1069.8,1020.7,849.5 \mathrm{~cm}^{-}{ }^{1}$ was contributed by the plant materials, and the absorption bands at $651.4,605.8 \mathrm{~cm}^{-1}$ was assigned to the $\mathrm{Fe}-\mathrm{O}$ stretching vibration.

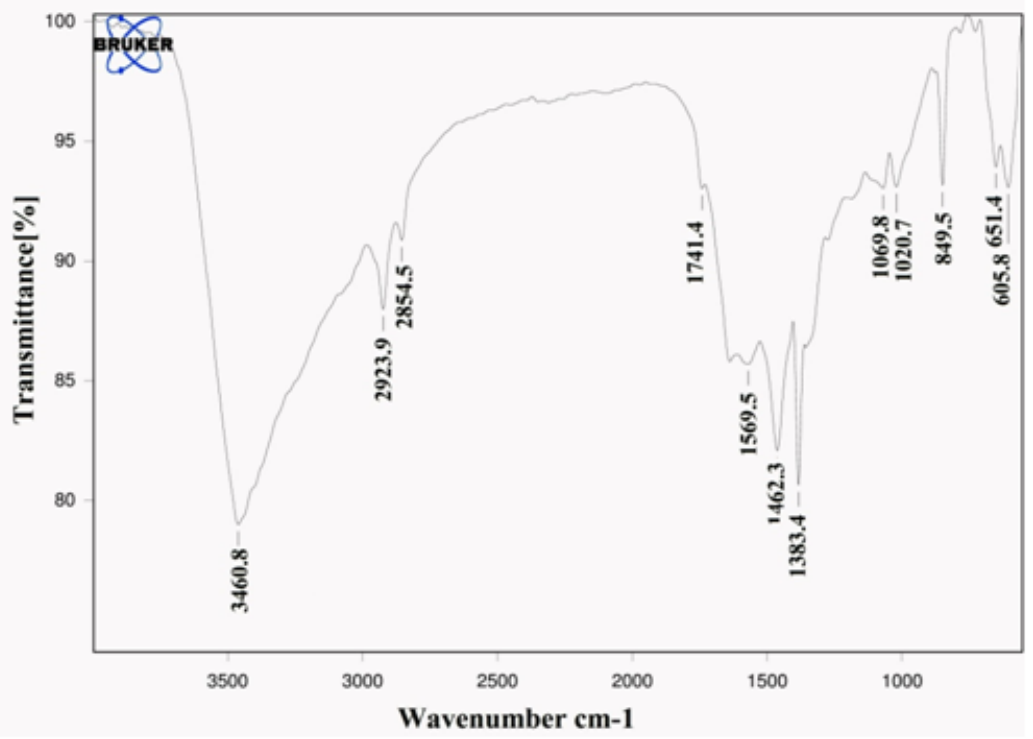

Figure 6. FTIR spectra of synthesized CPIO nanoparticles

\section{Acute toxicity studies}

The synthesized CPIO nanoparticles at a dose of $2000 \mathrm{mg} / \mathrm{kg}$ b.w was administered orally to the mice and no fur changes, eye secretion, respiration, any behavioral changes was occurred during the period. In addition to that clinical signs of toxicity like convulsions, tremors, salivation, nausea, vomiting, diarrhea, lethargy was also not observed. No mortality has occurred upto 14 days of treatment.

\section{Histopathology study}

The result obtained from histopathological sectioning was in agreement as there was no apparent damage to the brain, heart, and liver observed in the treated groups when compared with the control group shown in Figure7; no gross physiological changes were observed in control and CPIO nanoparticles treated 
mice. The histopathology of brain did not showed any abnormalities in brain and no degeneration of neurons was observed in both control and treated group. The myocardium of control and treated mice heart appeared normal without any clinical signs of toxicity. There was no inflammation observed in the liver. This study therefore confirmed that the CPIO nanoparticles were nontoxic to the brain, heart, and liver within the treatment durations. Test compounds did not cause any mortality at the dose level tested (i.e., $2000 \mathrm{mg} / \mathrm{kg} \mathrm{b}$.w) until the end of 14 days of observation.
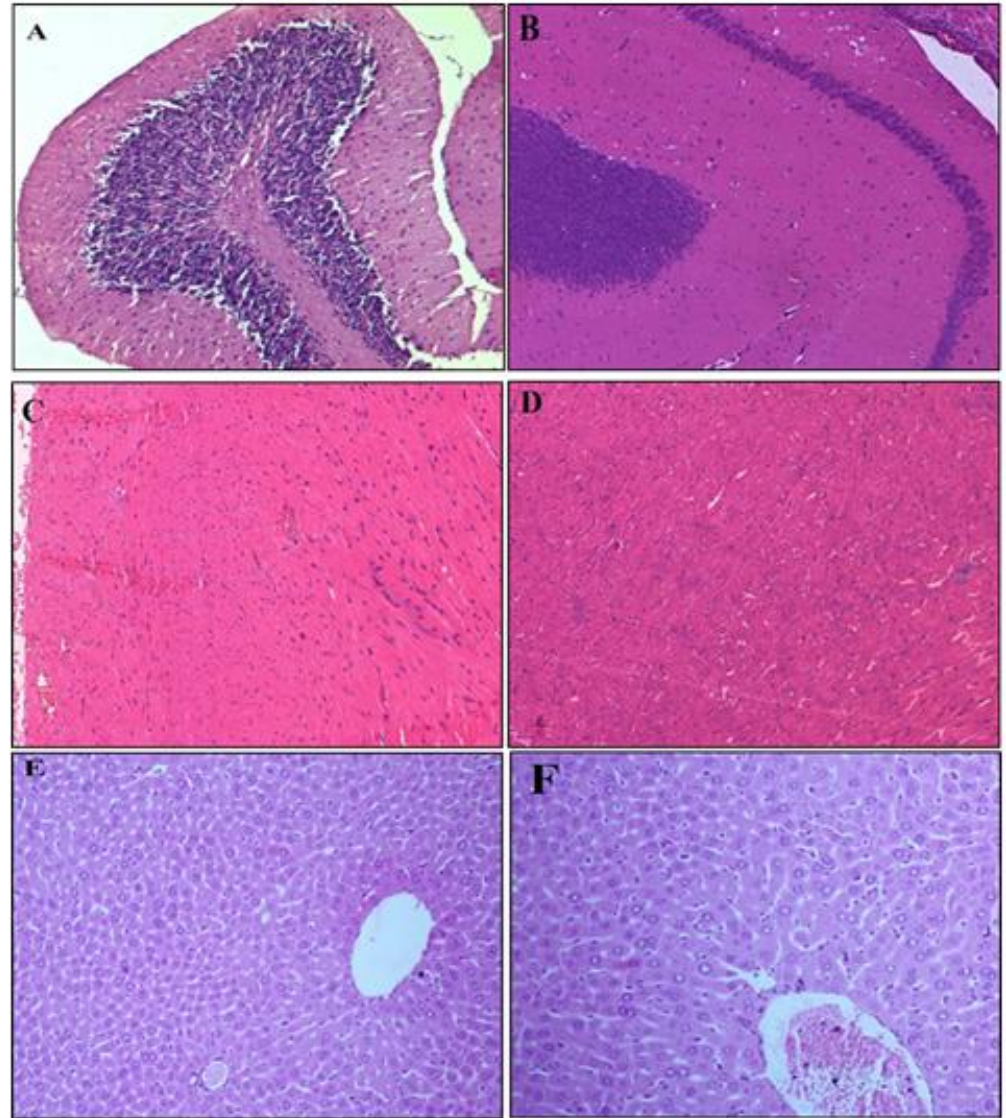

Figure 7. Control Brain, Heart, Liver (A, C, E respectively) and CPIO nanoparticles treated Brain, Heart, Liver (B, D, F respectively)

\section{Conclusions}

In this study, iron oxide nanoparticles were synthesized by a simple and green approach using the aqueous extract of Convolvulus pluricaulis without utilizing any chemical reducing agent and stabilizer. Based on the XRD analysis studied, it was confirmed that the synthesized iron oxide nanoparticle is a high purity crystalline $\gamma-\mathrm{Fe}_{2} \mathrm{O}_{3}$. FTIR spectroscopy analysis showed the involvement of biomolecules present in the aqueous extract of Convolvulus pluricaulis in the synthesis process. SEM and TEM results revealed the Capping of plant material around the synthesized CPIO nanoparticles at a scale of $50 \mathrm{~nm}$. The crystalline size of the synthesized CPIO nanoparticles was found to be $32.8 \mathrm{~nm}$ from XRD analysis, which is in an agreement with the result obtained from the TEM. Acute toxicity studies were carried out in Swiss albino mice at $2000 \mathrm{mg} / \mathrm{kg} \mathrm{b}$.w dose, and no mortality was observed during the 14 days study. In addition, histopathology studies are also in good agreement when compared with control group. Hence, the green synthesized nontoxic CPIO nanoparticles are expected suitable to be employed in various fields of applications, especially in biomedical applications.

\section{Acknowledgements}

I am thankful to the DST-INSPIRE for providing fellowship and I am grateful to the Head, CPS, IST, JNTUH, Hyderabad and CMR college of Pharmacy, Hyderabad for providing facilities to carry out this research work. 


\section{References}

[1] MA. Albrecht,CW.Evans, CL. Raston, Green chemistry and the health implications of nanoparticles, Green Chem, 8, 2006, 417432.

[2] AL.Kavitha, HG. Prabu, SA. Babu, SK. Suja, Magnetite nanoparticles chitosan composite containing carbon paste electrode for glucose biosensor application, J Nanosci Nanotechnol, 13(1), 2013, 98-104.

[3] MB. Gawande, RS. Varma, Nano-magnetite (Fe3O4) as a support for recyclable catalysts in the development of sustainable methodologies, Chem Soc Rev, 42(8), 2013, 3371-3393.

[4] NS.Sharad, RB.Swapnil, RM.Ganesh, SK.Samadhan, KM.Dinesh, BB.Shashikant, KR. Anuj, B. Nenad, MNDT. Orlando, Z. Radek, SV. Rajender, BG. Manoj, Iron oxide-supported copper oxide nanoparticles (nanocat-Fe-CuO): magnetically recyclable catalysts for the synthesis of pyrazole derivatives, 4-methoxyaniline, and ullmann-type condensation reactions, ACS Sustainable Chem Eng, 2(7), 2014, 1699-1706.

[5] BD. Terris, T. Thomson, Nanofabricated and self-assembled magnetic structures as data storage media, J Phys D Appl Phys, 38(12), 2005, R199-R222.

[6] M.Salem, Y. Xia, A.Allan, S. Rohani, ER. Gillies, Curcumin-loaded, folic acid-functionalized magnetite particles for targeted drug delivery, RSC Adv, 5(47), 2015, 37521-37366.

[7] XL. Li, H. Li, GQ. Liu, ZW. Deng, SL. Wu, PH. Li, ZS. Xu, HB.Xu, PK. Chu, Magnetite-loaded fluorine-containing polymeric micelles for magnetic resonance imaging and drug delivery, Biomaterials, 33(10), 2012, 3013-3025.

[8] KD.Wani, BS. Kadu, P.Mansara, P.Gupta, AV.Deore, RC.Chikate, P.Poddar, SD.Dhole, R.Kaul Ghanekar, Synthesis, characterization and in vitro study of biocompatible cinnamaldehyde functionalized magnetite nanoparticles (CPGF Nps) for hyperthermia and drug delivery applications in breast cancer, Plos One, 9(9), 2014, e107315.

[9] YP. Yew, K.Shameli*, M. Miyake, N. Kuwano, N. Bahiyah , A. Khairudin, S. Eva, B.Mohamad, KX. Lee, Green Synthesis of Magnetite (Fe3O4) Nanoparticles Using Seaweed (Kappaphycus alvarezii) Extract, Nanoscale Research Letters, 11,2016,276.

[10] CY.Haw, F.Mohamed, CH.Chia, S.Radiman, S.Zakaria, NM.Huang, HN.Lim, Hydrothermal synthesis of magnetite nanoparticles as MRI contrast agents, Ceram Int 36(4),2010,1417-1422.

[11] RR.Qiao, CH.Yang, MY.Gao ,Superparamagnetic iron oxide nanoparticles: from preparations to in vivo MRI applications, $J$ Mater Chem 19(35),2009,6274-6293.

[12] S.Laurent, D. Forge, M.Port, A.Roch, C.Robic,LV. Elst, RN. Muller, Magnetic Iron Oxide Nanoparticles: Synthesis, Stabilization, Vectorization, Physicochemical Characterizations,and Biological Applications, J Chem Rev, 2008, 2064-2110.

[13] J. Liu, SZ. Qiao, QH.HU, GQ.Lu, Magnetic nanocomposites with mesoporous structures:synthesis and applications, Small,7, 2001, 425-443.

[14] S.Iravani, Green synthesis of metal nanoparticles using plants, Green Chem., 13, 2011, 2638-2650.

[15] KN.Thakkar, SS.Mhatre, RY.Parikh, Biological synthesis of metallic nanoparticles. Nanotechnol. Biol.Med. Nanomed,6, 2010, 257-262.

[16] L. Sintubin, W. Verstraete, N. Boon, Biotechnol. Bioeng, 109, 2012, 2422-2436.

[17] RH.Singh, K.Narsimhamurthy, G.Singh, Neuronutrient impact of Ayurvedic Rasayana therapy in brain aging, Biogerontology, 9(6), 2008, 369-74

[18] J.Malik, M.Karan, K.Vasisht, Nootropic, anxiolytic and CNS-depressant studies on different plant sources of shankhpushpi. Pharmaceutical biology, 49(12), 2011, 1234-42.

[19] NK.Sethiya, A.Nahata, SH.Mishra, VK.Dixit. An update on Shankhpushpi, a cognition-boosting Ayurvedic medicine, Journal of Chinese integrative medicine, 7(11), 2009, 1001-22.

[20] A.Nahata, UK.Patil, VK.Dixit, Anxiolytic activity of Evolvulus alsinoides and Convolvulus pluricaulis in rodents, Pharm Biol., 47(5), 2009, 444-451.

[21] D.Dinesh, V.Rekha, Screening for antidepressant-like activity of Convolvulus pluricaulis choisy in mice, Pharmacologyonline,1, 2007,262-278.

[22] SW.Bihaqi, M.Sharma, AP.Singh, M.Tiwari, Neuroprotective role of Convolvulus pluricaulis on aluminium induced neurotoxicity in rat brain, J Ethnopharmacol., 124, 2009, 124,409-415.

[23] JP.Joshi, JP.Kamat, H.Mohan , Antioxidant effects of Convolvulus pluricaulis in rat brain mitochondria against oxidative damage induced by gamma radiation and photosensitization, BARC Newslett,249, 2004,183-187.

[24] KR.Kshirod, SM.Sthiti, Anticonvulsant activity of Shankhapuspi (Convolvulus pluricaulis Chois) on Strychnine induced seizure in experimental animals, International journal of ayurvedic medicine, 3(2), 2012, 82-87.

[25] NK. Sethiya, A.Trivedi, MB.Patel, SH.Mishra, Comparative pharmacognostical investigation on four ethanobotanicals traditionally used as Shankhpuspi in India, J Adv Pharm Technol Res.,8, 2010, 123

[26] P.Agarwa , B.Sharma, A.Fatima, SK.Jain, An update on Ayurvedic herb Convolvulus pluricaulis Choisy, Asian Pac J Trop Biomed., 4(3), 2014, 245-252.

[27] S. Sandeep, AS.Santhosh, NK. Swamy, GS.Suresh, JS. Melo, P.Mallu, Biosynthesis of silver nanoparticles using Convolvulus pluricaulis leaf extract and assessment of their catalytic, electrocatalytic and phenol remediation properties, Adv. Mater. Lett. 7(5), 2016, 383-389.

[28] FQ.Hu, L.Wei, Z.Zhou, YL.Ran, Z.Li, MY.Gao, Preparation of biocompatible magnetite nanocrystals for in vivo magnetic resonance detection of cancer, Adv Mater, 18(19),2006, 2553-2556.

[29] H.Zhao, K.Saatchi, UO.Häfeli, Preparation of biodegradable magnetic microspheres with poly(lactic acid)-coated magnetite, $J$ Magn Magn Mater, 321(10), 2009,1356-1363.

[30] L.Zhang, WF.Dong, HB.Sun, Multifunctional superparamagnetic iron oxide nanoparticles: design, synthesis and biomedical photonic applications, Nanoscale 5(17), 2013, 7664-7684.

[31] P. Berger, NB.Adelman, KJ.Beckman, DJ.Campbell, AB.Ellis, GC.Lisensky, Preparation and Properties of an Aqueous Ferrofluid, J. Chem. Ed.,76, 1999,943-948.

[32] OECD Guideline. (2001) on acute oral toxicity (AOT) Environmental health and safety monograph series on testing and adjustment number 425. https://ntp.niehs.nih.gov/iccvam/suppdocs/feddocs/oecd/oecd_gl425-508.pdf.

[33] G.Madhubabu, S. Yenugu, Effect of continuous inhalation of allethrin-based mosquito coil smoke in the male reproductive tract of rats, Inhal Toxicol, 24,2012,143-152. 